\title{
A POLÍTICA, A EDUCAÇÃO SOCIAL E A TERCEIRA IDADE*
}

\author{
Jorge Gilberto Krug**
}

\section{Resumo}

O texto privilegia os eixos interdisciplinares e de intervenção presentes na Política Social, na Educação Social e os articula com os elementos análogos contidos na Gerontologia. A educação presente ao longo da vida humana se amplia com os elementos político-sociais da participação. Esta participação é educativa e há um aprendizado a quem dela se apropria em um trabalho coletivo que está presente nos inúmeros grupos sociais da chamada Terceira Idade, bem como seria necessário estar presente nas instituições ditas de proteção social. No entanto, este aprendizado político-social e interdisciplinar está imerso em um mundo de incertezas que acompanha o processo de envelhecimento e a própria velhice.

Palavras-chave: Política Social. Educação Social. Gerontologia. Terceira Idade.

\section{Introdução}

Para refletir o tema proposto no âmbito da Gerontologia ousaria obter apoio em Corteletti (2002, p. 59), quando introduzindo suas reflexões, disse:

[...] faz-se necessário refletir sobre a frase que envolve o tema, visto que a mesma se apresenta diante de nós em sua compreensão total. O pensar a frase no seu todo nos possibilita perceber a relação entre os termos que a formam e o significado que o tema contém, o qual constituí-se num desafio. Adentrar na frase nos oportuniza analisar compreensivamente as suas partes constituintes e retornar a sua

\footnotetext{
* Texto original produzido para o IV Congresso Sulbrasileiro de Geriatria e Gerontologia de 03 a 06/09/2003 em Porto Alegre. Posteriormente, revisado e atualizado pelo autor em 2005.

** Graduação em Serviço Social pela Pontifícia Universidade Católica do Rio Grande do Sul (PUC-RS). Pós Graduado - Especialização e Mestrado (PUC-RS). Doutor em Filosofia e História da Educação pela Universidade de Santiago de Compostela - Espanha. Professor e Pesquisador na Universidade de Caxias do Sul (UCS). Membro da Equipe do Programa Universidade da Terceira Idade da Pró Reitoria de Extensão (UCS). E-mail: jorgegilkrug@ig.com.br
} 
totalidade, alcançando uma compreensão mais aprofundada de sua significação. Assim é que ao separá-la em seus elementos constata-se que é uma prática pedagógica, socioeducativa, que assume a intencionalidade de um processo que procura desenvolver as potencialidades de cada indivíduo de modo pessoal e de cada grupo que integra a comunidade e revelar simultaneamente a reflexão e a praxis pedagógica.

E que acrescentaria: praxis político-crítico-pedagógica. Neste sentido, procuraria o elemento que uniria Gerontologia Social à Política, à Educação Social e à Terceira Idade. Tendo presente a contribuição de Sá (1999), quando trata a interdisciplinaridade na Gerontologia, de que ela é ciência interdisciplinar e interventiva no processo de envelhecimento de modo a provocar mudanças. Esta natureza interventiva está voltada para a longevidade e qualidade de vida, e um dos elementos desta qualidade é a cultura. A autora citada vai além ao dizer que a Gerontologia é produto ou reflexo da realidade social e das relações sociais; que está relacionada às questões sociais como: demografia e políticas sociais, modelos de produção, desigualdades sociais e exercício pleno da cidadania com participação e luta pelos direitos fundamentais.

Esta mesma ação interventiva está presente na Política e na Educação Social e mais propriamente na Terceira Idade que longe está de ser passiva como querem certos modelos sociais, mas sim extremamente ativa por sua bagagem e que não raro exerce um poder presente no cotidiano. Segundo Attias-Donfut $^{1}$ (p. 12) apud Sá, haveria uma teoria a referendar esta constatação: "[... ] a da dialética entre história individual e a estrutura social".

Se a Gerontologia, é tida como estudo da pessoa idosa e em seu qualificativo social inclui vários aspectos, como antropológicos, psicológicos, legais, sociais, ambientais, econômicos, éticos e políticos de saúde, entendese que os educativos e político-sociais, não podem ser olvidados.

O idoso, salvo em condições especiais, não perde sua capacidade de aprender e continuar se educando, bem como, não perde sua condição básica de animal político.

Trata-se de se educar como idoso para as novas exigências de participação social. Isto implica, conforme Petrus Rotger (1997, p. 23),

1 ATTIAS-DONFUT, Claudine. Seminários de Estudos sobre a Terceira Idade. Cadernos da Terceira Idade, São Paulo, n. 3a e 3b, p. 1-52; 1-54, 1979. Apud SÁ, 1999, p. 225. 
[... em melhorar as relações com os companheiros de idade. [... ] Significa preparar o cidadão para operar com habilidade social no âmbito das várias relações, gerar mudanças de atitude frente a abertura e subculturas, ou seja, ser responsável e assumir os princípios de uma justa convivência social.

Ainda no dizer do mesmo autor citado (p. 29), a educação social é entendida como " [ . . ] formação social e política do indivíduo, como educação política do cidadão".

Em uma educação que busca visibilizar um processo de empoderamento comunal. Por ele é possível se desenvolver um trabalho projetado e, conseqüentemente, transformador. Isto o qualifica como político e por ele e nele há um aprendizado que conscientiza, capacita e organiza os sujeitos pela via do coletivo.

Ortega y Gasset ${ }^{2}$ apud Petrus Rotger, concebia a educação social desde uma dupla perspectiva: “ [ . . . ] por um lado como estratégia para inserir o cidadão em sua sociedade e por outro, como programa político capaz de transformar a sociedade".

Uma educação que, segundo Caride Gòmez (1998), ao enfatizar o social, pretende que as políticas educativas sejam contempladas na perspectiva mais complexa das políticas sociais, multiplicando os atores pedagógicos, os espaços e tempos de educar, as dinâmicas da socialização e da aprendizagem, as metodologias e os recursos - uma educação que se contextualiza em cada realidade social nos centros culturais, nos movimentos associativos, nas ruas, nas cidades, nos processos de animação e desenvolvimento comunitário na inserção e reinserção social, nos tempos livres e nas dinâmicas de trabalho.

Por fim, na busca da interrelação contida ou implícita no título do trabalho e retomando Petrus Rotger (1997, p. 32), se vê que uma das funções da educação social é " [... ] além de dar respostas às necessidades existentes, criar consciência acerca de quais são os direitos sociais do cidadão, de todos os cidadãos, e gerar novas demandas de educação social".

As reflexões em seqüência seguem, portanto, a lógica do real complexo gerontológico e o privilegiamento dos aspectos políticos e educativo-sociais no contexto da Terceira Idade através dos seguintes pontos:

2 ORTEGA Y GASSET, José. La pedagogia social como programa politico. In: . Obras Completas. 7. ed. Madri: Revista de Occidente, 1966. Tomo I. Apud PETRUS ROTGER, 1997, p. 27. 
a) um envelhecer aos sobressaltos da incerteza e as conquistas sociais a perigo;

b) a Política e Educação Social como parceiros coadjuvantes na Gerontologia;

c) considerações finais.

O tema vem merecendo sucessivos estudos na pressão de eventos nacionais e internacionais patrocinados ou pelas Nações Unidas, ou pelos governos nacionais, ou por organizações não governamentais Nacionais, ou Internacionais, ou mesmo por Universidades, quase sempre com a participação ativa da Terceira Idade.

\section{Um Envelhecer aos Sobressaltos da Incerteza e as Conquistas Sociais a Perigo}

Longe ficaram, antes da primeira metade do século $\mathrm{XX}$, as certezas da vida das classes burguesas quando as incertezas dos modelos econômicos capitalistas se tornaram mais evidentes.

O futuro possível em suas predições vem desmoronando a cada novo tipo de conflito mundial. Fala-se na civilização da incerteza ${ }^{3}$ e se busca construir propostas de curta duração com um mínimo de equilíbrio dinâmico onde, praticamente, o viver cotidiano é um misto de futuro com uma certeza do passado.

A par disso, significativas mudanças previsíveis na demografia apontam para um envelhecimento da humanidade ou para sua sempre sonhada longevidade.

Se isto é real, o ser humano busca construir caminhos, propostas, políticas, programas e projetos que atendam estas novas realidades e suas complexidades.

Aí estão, no caso da Terceira Idade, a Geriatria e a Gerontologia com suas políticas ao lado de uma série de outras não raro concorrentes e conflitantes em sua natureza de poder.

Estes conflitos de poder são alimentados pelas desigualdades sociais e deixam visível a fragilidade e as incertezas das políticas criadas para apaziguar as incertezas atuais e futuras. Boaventura Santos (2002, p. 23) diz que: "Só

3 Sobre o tema leia: NÚÑEZ PEREZ, Violeta (Coord.). La educación en tiempos de incertitumbre: las apuestas de la Pedagogia Social. Barcelona: Gedisa, 2002. 
há políticas sociais, porque a política dominante é anti-social”. Ou seja, no afã de querer acertar, se está partindo de premissas com tendências ou bases pensadas em um mundo de certezas e dogmas que não resistem ao cotidiano. A própria violência passa a ter coerência ante um pacifismo obsoleto.

Neste mesmo contexto aparentemente fragilizado onde o ser humano em qualquer idade aparece enfraquecido, desrespeitado em seus direitos individuais, sociais e políticos, é que sempre renasce, dialeticamente, a luta inconforme contra esta realidade que tenta ser lógica e coerente, de uma ânsia de consciência crítica, de capacitação, de organização participativocrítica para melhorar as incipientes conquistas sociais e de tornar plena, mesmo que efêmera, a possibilidade do exercício da cidadania em um mundo possível.

É importante não se olvidar as "ondas dos direitos"'4 que não chegam a ser cumulativas, mas se desenvolvem nesta expectativa porque conduzidas por homens e mulheres. Considera-se a primeira onda como a dos direitos civis - a separação da sociedade e do estado - o início do confronto entre Sociedade e Estado e que perdura até hoje, por exemplo, no âmago dos conselhos. A onda dos direitos políticos de votar ser votado, de se poder organizar desde dentro do próprio Estado pela via do voto. A onda de direitos sociais que reflete a necessidade de se buscar a conservação sempre melhorada destes direitos e que, não raro, tentam tornar letra inoperante por modelos econômicos elitizantes. A onda dos direitos ecológicos, que muito exigem da visão interdisciplinar para ser efetivo e onde outros seres como espécies animais e vegetais passam a gozar de direitos. Onda esta que traz em seu bojo as discussões da genética e das células tronco e toda a implicação para o viver e conviver do ser humano.

O século deixou um legado de conflitos de interesses não resolvidos, de construção de paz entre as Nações, quase sempre por cima de muito sangue derramado.

De um modo geral, os senhores da guerra têm mais de 60 anos, o que desmente a acertiva generalizante de que quanto mais idade, mais sabedoria e tolerância.

Na verdade, até mesmo os direitos são abominados em favor de um dever de submissão. E aí se confunde o direito com o autoritarismo (daquele que nada fez e agora entende que a ele tudo é possível).

4 Sobre o tema ler SORJ, Bernardo. A Nova Sociedade Brasileira. 2. ed. revisada. Rio de Janeiro: Jorge Zahar, 2001. 
São eles que têm fundamentado as guerras onde quase sempre são os jovens os sacrificados. A mídia, que usa e abusa da memória que se esvanece rapidamente em um mundo a-eticamente globalizado, trabalha com o perpétuo jovem, enquanto o velho é esquecido ou lembrado nas decisões de guerras. As decisões, as mediações de conflitos e as invasões são premeditadas pelos mais velhos que, não tendo o poder da juventude, têm o poder do espaço que não abrem aos novos. É a busca da eternidade no poder, a repetida volta ao poder, seja por golpes na democracia ou por eleições, não raro fraudadas, ou porque todos assim querem e as eleições e reeleições sempre voltam. Quase sempre o velho dirigente diz: "eu vou voltar!" e este voltar será, de modo geral, um período difícil, um período de desilusões, pois mesmo o velho esqueceu que nada se repete e o que está presente é sempre o desejo da perpetuidade. Neste sentido, jovens e velhos se assemelham em sua ânsia de perpetuidade, de fixação no presente, não olhando para as certezas do passado e com medo real das incertezas do futuro.

Em recente livro Schirrmacher (2005) antevê que esta luta intergeracional que hoje pende, aparentemente para o velho, e que é uma luta política, na verdade pende para o jovem que busca eliminar o velho inativo, peso previdenciário. Em futuro próximo, nem bem 40 anos, serão efetivamente os velhos que buscarão eliminar os novos.

Neste ir e vir se confunde revisão de conceitos com atitudes oportunistas do presente, tudo se banaliza, naturaliza e relativiza. Nada tende a se perpetuar, mas nem tudo é por demais efêmero. No contexto, por exemplo, das conquistas sociais, se observa que o mundo é desigual e desigual no trato da desigualdade. Não raro uns impõem sobre outros possíveis resultados, metas, objetivos e políticas sociais. Simplesmente se impõe modelos de vida como se os próprios fossem os únicos e perfeitos no mundo. Com tudo isso, ainda falta muito para que os direitos sociais de alimentação, habitação, educação, saúde, previdência, segurança, entre outros, sejam alcançados e sequer consolidados.

Em um país como o Brasil, que tenha a denominação mais sofisticada que se queira dar, mas que não passa globalmente de um país que se esforça por não ser colônia, não ser satélite, dependente, terceiro-mundista e que outros títulos tenha, as parcas conquistas sociais continuam a ser tratadas como assistencialismo, benevolência ou apaziguamento emergencial de conflitos.

Não raro se afirma que o povo já tem favores demais e tudo se perde no emaranhado do senso comum ou do bom senso como muito bem expressa Gennari (2002). 
As poucas conquistas sociais que levaram anos para serem realidade estão hoje a perigo. É verdade que não raro estão entremeadas de casuísmos, de exceções e múltiplos parágrafos capciosamente redigidos em nome dos usuários. O que está evidente é que não se discute a espinha vertebradora das políticas sociais, não se discute que suas não políticas são as mais perniciosas e que não há interesse real em aprofundá-las, universalizá-las, descentralizá-las no rumo de um usuário que se capacite, tenha consciência e se organize na luta:

a) primeiro, para ter acesso;

b) segundo, para geri-las;

c) terceiro, para torná-las um dever sem exceções.

Há no país um processo acelerado de envelhecimento. Há conquistas sociais incompletas. E há uma incerteza geral, não só no futuro, como no presente; não só para os titulares da Terceira Idade, como também para os que virão compor no futuro esta faixa-etária. A leitura da incerteza não se limita ao país, mas ao mundo globalizado em uma ação de interesses não muito evidentes quanto à ética humana.

A Gerontologia não pode atuar apenas em uma visão terapêutica ou preventiva, mas igualmente em uma visão política de cunho educativo-social, de cunho interventivo, efetivamente de mudança nos parâmetros gerais da sociedade. Uma ação participativo-crítica, contextualizada, pela via de inúmeras organizações da sociedade e do Estado, propositiva e coresponsável quanto aos resultados. Tratar-se-ia, quem sabe, de uma Gerontologia Política. Ela não se fecha em si, no seu sujeito o idoso, mas traz consigo, em seu desenvolvimento, um processo educativo-social de constante aprendizagem coletiva, de aprendizagem interdisciplinar ou ecológica.

\section{A Política e Educação Social como Parceiros Coadjuvantes na Gerontologia}

Em um mundo de incertezas no presente e um futuro incerto o que pode ser mais certo que o existir humano, que o agir humano em todas as fases da vida? Não há mais o mundo feito nem o caminho já percorrido onde não há mais nada para se aprender. Tudo é novidade, surpresa, embora, não raro, sejam situações antigas sob nova roupagem.

A educação é permanente. Aprende em todos os espaços, com todos os fatos e quase sempre com gente. Petrus Rotger (1997, p. 9) diz que: "Seja 
qual for o enfoque desde o qual se contempla a educação social, esta virá determinada por suas duas características mais distintas: seu âmbito social e seu caráter pedagógico".

Aqui, interessa refletir sobre o âmbito social da educação social que já vem sendo estudada desde o século XIX. Apesar de se viver sob uma égide ou hegemonia de marketing individualista, hedonista, utilitarista e pragmatista, ou mesmo pseudo-social, existem outras modalidades de viver, de educar, de trabalhar, de pensar, de construir e sonhar. Uma delas é pela via da educação social.

Já com Natorp (1999), se tem que a consciência se desenvolve no homem em uma relação mútua de consciência à consciência. A evolução das relações a partir disso (consciência de cada um) é que se chega a entender a comunidade - $o$ total. Há necessidade de conexão entre as pessoas em uma comunidade para que se entenda uma conexão universal, segundo o mesmo autor citado. De acordo com seu pensamento, $a$ comunidade é não somente o lugar de encontro dos indivíduos, senão também a forja que lhes infunde, pela educação, o necessário espírito comunitário tido como essencial à vida humana. Toda atividade criadora se realiza com base na comunidade. Por este entendimento, a consciência se faz dialetizada entre o indivíduo em si e o indivíduo em relação com o outro. O homem se torna homem somente pela via da comunidade humana . Não é uma justaposição, mas um interinfluir constante. A própria educação sem a comunidade não existe. Envolver-se com o todo comunal eqüivale a ampliar o eu.

Caride Gòmez diz que a educação social, citando Gimeno Sacristan ${ }^{5}$ (p. 114):

[... ] está presente na construção de redes sociais. Estas redes aspiram que as políticas que regulam a educação social sejam contempladas na perspectiva mais ampla e complexa das políticas sociais, ou seja, no objetivo educativo de uma sociedade humana e socialmente desejável. Ela tem buscado ser coerente com a vontade de integrar, criar coesão, ou transformar a sociedade mediante propostas educativas, orientadas a favorecer o desenvolvimento humano, mostrando-se especialmente sensível com respeito pelas liberdades, a conquista da equidade e da promoção da justiça social.

\footnotetext{
${ }_{5}^{5}$ GIMENO SACRISTAN, José. Educar y convivir en la cultura global: las exigencias de la ciudadania. Madrid: Morata, 2001. Apud CARIDE GÒMEZ, 2002, p. 32.
} 


\section{É fundamental visualizar as relações entre a sociedade e a educação}

social:

a) como uma educação social em sociedade: o cenário é crítico e ensina ou se aprende a sobreviver. Há uma evolução do aprendizado, da intervenção desde dentro da comunidade, articulado ou não com uma intervenção desde fora da comunidade;

b) como uma educação social da sociedade: como uma visão de algo sempre necessário;

c) como uma educação social por uma sociedade: algo a ser constantemente alcançado pela via coletiva;

d) como uma educação social para uma sociedade: buscar resgatar o tudo que vem sendo perdido e se tal não for feito será impossível avançar;

e) como uma educação com a sociedade: que seja ao menos com um de seus atores e autores, no caso os idosos. Numa espécie de "subversão da ordem estabelecida", alianças que, enfrentando resistências aprendem a resistir e a superar conflitos.

Nusberg $^{6}$ (p. 396) citado por Caride Gòmez diz:

Em um mundo menos ideal em que vivemos, realmente, os direitos educativos dos de mais idade devem ser promovidos ativamente de modo que os anciãos sintam que têm direito a participar em uma formação continuada. Uma vez mais fica visível a convicção de que os processos formativos não tem idade, sendo um suporte fundamental de qualquer tentativa orientada ao crescimento pessoal e ao desenvolvimento das sociedades.

Caride Gòmez, citando Fernández-Ballesteros ${ }^{7,8}(1992,2000)$, reafirma

[ . . ] ] a necessidade de se promover uma ação gerontológica-educativo-social orientada a modificar os mitos que

${ }^{6}$ NUSBERG Charlotte. Educacional Opportunities for the Ederly Industrialized Countries Outside the United States. Educacional Gerontology, Washington, n. 4, p. 395-409, 1982. Apud CARIDE GÒMEZ, 2002, p. 43.

${ }^{7}$ BALLESTEROS FERNANDES, Rocio. Mitos y realidades sobre la vejez y la salud. Madrid: SG; Fundation Caja, 1992. Apud CARIDE GÒMEZ, 2002, p. 43.

8 Gerontologia Social. Madri: Pirâmide, 2000. 
impregnam as percepções sociais que existem acerca das pessoas idosas; e por extensão, a promover uma cultura de respeito e estima para com a velhice, fortalecendo os significados pedagógicos próprios das relações intergeracionais, favorecendo a corresponsabilidade dos idosos na tomada de decisões, facilitando sua integração social nas dinâmicas institucionais e comunitárias ou animando a convivência que se fundamenta na experiência, na pluralidade e diversidade que acumulam as pessoas de mais idade.

E segue Caride Gòmez (2002, p. 43) dizendo que " [ . . . ] são metas que precisam ser garantidas por políticas sociais para a velhice"; e acrescentaria com a velhice;

[... e que abranjam o acesso eqüitativo aos serviços de saúde e assistência social, a proteção via auxílios de suficiência econômica [renda mínima], de prevenção e satisfação de necessidades via sistema de serviços sociais, a ampliação de oportunidades que são oferecidas pela educação e cultura ou a participação nas instituições e movimentos sociais [lutas sociais] que compõem a vida cotidiana.

Esta educação social não age fora de um contexto político permeado de conflitos entre a sociedade, o Estado e o mercado; ao contrário deles, se nutre dialeticamente e propõe ações que envolvem o todo da Gerontologia. O idoso, por haver chegado à Terceira Idade, não está dispensado de agir, pensar, propor, eleger, conferir, fiscalizar. Não pode ser dispensado, não é parte do exército dos descartáveis da reestruturação produtiva. É um ser vivo político de direitos, com uma bagagem invejável de vida, com risco de desaparecer a qualquer momento como qualquer outro ser vivo.

Hoje, mais do que nunca, em um mundo não satisfatoriamente globalizado, mas já suficientemente forte para desestimular as vivências e experiências locais e comunais, urge que se continue construindo espaços multivariados de aprendizado e valor local, onde, segundo Demo (1994), algumas políticas participativas precisam ser estimuladas, como: as que desenvolvem pela educação a consciência crítica; as que cultivam as identidades culturais; as que trabalham com as alternativas comunitárias de comunicação; as que se dedicam à defesa do consumidor, do ambiente e dos direitos humanos; as que buscam atenção para as "minorias" como os idosos, os "sem"(em referência aos movimentos dos sem teto, sem emprego, sem alimento, sem terra) e outros; as que reconstroem os desgastados e esvaziados 
partidos políticos, devolvendo aos cidadãos a noção viva da pluralidade democrática; as políticas que se desenvolvem nos perigosamente tornados obsoletos sindicatos operários e as que buscam desenvolver novas perspectivas de segurança pública, não permitindo o nefasto negócio da construção dos ghetos de pobres e ricos. Enfim, aquelas políticas participativas que buscam construir e efetivar uma nova sociedade civil embasada na miríade de novos projetos de base popular que não mais aceitam as intervenções autoritárias do Estado ou de suas elites quando se sentem ameaçadas por realidades que elas mesmas criam. Tudo somado a uma série de outras formas associativas com larga experiência de luta por seus objetivos e causas.

Hoje, mais do que nunca, isto vem sendo uma nova realidade não de todo percebida e que transparece nos direitos sociais gravados constitucionalmente e na operacionalidade dos mesmos pela via dos Conselhos representativos, participativos, políticos e de co-gestão Estado-Sociedade, inclusive a nível local. Significa que há uma cultura nova sendo gestada constantemente nas culturas já existentes, uma cultura solidária-participativa, crítica e propositiva. É o conteúdo novo de uma qualidade de vida renovada, objetivo perseguido pela natureza interventiva da Gerontologia.

Trata-se de uma Gerontologia presente no cotidiano de enfrentamento dos idosos e que desenvolve um novo aprendizado. $\mathrm{O}$ aprendizado protagônico das ruas, do próprio bairro, diante de uma globalização avassaladora; o locus, por suas instituições da gestão e gestação das políticas, programas e projetos sociais. É onde a questão social e seus efeitos são mais visíveis, é onde se aprende e onde há uma educação e uma pedagogia que permeia as ações políticas de solução e de entendimento do que ocorre inclusive na macro-realidade. Neste sentido a comunidade é um espaço privilegiado onde ocorre a educação social dos indivíduos e dos grupos.

Quintana Cabanas ${ }^{9}$ citado por Caride Gòmez afirma que na comunidade existem duas características: a mudança social e o caráter pedagógico. É o locus onde se aprende a fazer política e onde a política tem um caráter pedagógico interventivo-social. Dentro deste processo o cidadão (o idoso) se capacita, ao participar do estudo, da análise, da deliberação e da decisão através de um trabalho social coletivo, na realidade de desigualdades vividas nas comunidades, e dos projetos em busca das soluções. É o caminho

9 QUINTANA CABANAS, José María. Pedagogia social. Madrid: Dykinson, 1984 Apud CARIDE GÒMEZ, p. 36, 2002. 
para a concretização das redes comunitárias que instruem o processo da chamada “cidade educadora" desenvolvidas por Villar (2001).

Se a natureza interventiva da Gerontologia está voltada para a longevidade e a qualidade de vida, está situada no cadinho pedagógico político da comunidade ou no locus do aprendizado da ação pensada coletivamente, ou no locus do aprendizado da intervenção coletiva na realidade. Caride Gòmez (1997, p. 222) vê a comunidade como "[ . . . ] um processo pedagógico através do qual se ativa o protagonismo de cada sujeito no desenvolvimento social desde os menores grupos sociais até os extensos limites da sociedade global" com suas redes institucionais e organizativas. A comunidade deixa de ser tida como algo nostálgico e abstrato para ser um processo de vida e de trabalho social em caminho protagônico. É o local de aprendizado cotidiano dos sujeitos agrupados ou não. Significa que o agir na comunidade pelos sujeitos é um aprendizado sócio-político que instrui o conceito de qualidade de vida e redimensiona a longevidade. Ambos deixam de ser algo individual-egoístico para ser real coletivo, porque aprendido socialmente.

Mas interroga-se: a comunidade tem sido tida de modo políticoeducativo e social, em seu desenvolvimento por suas entidades para aprofundar e fundamentar a construção de cidadãos livres, responsáveis, críticos, propositivos e plenamente conscientes da sociedade em que vivem? Isto transparece um desafio quando se busca trabalhar a realidade da qualidade de vida da pessoa idosa em suas relações, inclusive intergeracionais. A intervenção para consecução disto soa como radical mudança nas incipientes redes sociais protetivas de tais cidadãos. Urge intervir na direção de um processo sócio-político-educativo de participação critica através de projetos gestados com os próprios idosos e que embasem e estejam lastreados por uma educação emancipadora e políticas sociais justas e equânimes.

Trata-se, conforme diz Núñez Perez ${ }^{10}$ (1999), citada por Caride Gòmez e Meira Cartea, "[ . . . ] de serem sujeitos atores convocados a pensar e a pensar-se de um modo novo na sociedade que começa a navegar pelo terceiro milênio".

${ }^{10}$ NÚÑEZ PEREZ, Violeta. Pedagogia social: cartas para navegar en el nuevo milenio. Buenos Aires: Santillana, 1999. Apud CARIDE GÒMEZ; MEIRA CARTEA, 2000, p. 37. 


\section{Considerações Finais}

Entende-se que a Gerontologia está situada tanto quanto seu objeto - o sujeito idoso e suas relações, relações sociais, econômicas, políticas e culturais; situada no locus comunal e universal contextualizado e histórico. Como tal, supõe estar impregnada de uma ação interventiva que objetive a mudança e uma sempre renovada qualidade de vida. No entanto o mudar é ato político interventivo que supõe realidade e recursos, supõe planejamento, prioridades e participação estratégica. A participação dos sujeitos supõe novos atos interventivos num aprendizado constante de fracassos e sucessos no embate com o Estado e o Mercado. Este aprendizado se faz aprendendo dentro de uma pedagogia e educação social que qualificam a intervenção pela qualidade de vida. Trata-se de uma educação que conscientiza, capacita e organiza os atores para serem também autores coletivos de suas histórias, mesmo no âmbito da saúde, do lazer, da recreação e da espiritualidade, não descurando, mas resignificando as diferenças e singularidades de cada um.

A intervenção presente na Gerontologia e em seus elementos coadjuvantes, como na política, e aí nas políticas sociais e na educação e pedagogia social, ${ }^{11}$ é condição essencial para mudar o quadro de incertezas que cerca o cidadão, e, mais especificamente, o idoso.

Os idosos envolvidos por uma nova atmosfera da Gerontologia não apenas buscam seu bem estar individual, mas, sobremodo, em conjunto, aprendem a aprender a construção de lutas e movimentos sociais a partir de seus projetos coletivos para, não só manterem e aperfeiçoarem as conquistas que já alcançaram, como buscar novas pois, o bem-estar ainda está mais para mal do que para bem-estar.

A qualidade de vida individual só está assegurada se a qualidade coletiva de vida é o resultado alcançado nos conflitos entre a sociedade e o Estado. Há que haver mobilização constante, pressão e proposição por todos os canais legais, mas é importante ter presente o que se está aprendendo em conjunto em um processo emancipatório.

Por fim, tem-se presente que tudo isso está em desenvolvimento, e que idosos e cientistas, não raro cientistas idosos, são chamados na descons-

\footnotetext{
${ }^{11}$ Ver SÁEZ CARRERAS, Juan (1993) - Quando trata da intervenção como prática social, critica que aponta no compromisso, na participação e na democracia; assim como Petrus Rotger, Antonio Juan (1997) produz uma aproximação conceitual, onde destaca a educação social como uma didática do social.
} 
trução a construírem juntos sempre novas possibilidades, reconhecendo seus próprios limites, mas que em conjunto se minimizam.

Isto significa uma Gerontologia reconceituada que abrange tanto o idoso institucionalizado como o que vive em sua comunidade, não se olvidando aí, uma relação sempre possível.

A vida continua e há, portanto, muito que aprender: sobre o cotidiano da saúde e suas políticas e programas; o convívio com um ambiente em preservação; a informação crítica-econômica e legal, que ajuda na tomada de decisões; o uso dos espaços públicos nas ruas e nos transportes; o uso adequado da Gerontotecnologia; o posicionamento bioético; a gestão participativa institucional e a gestão comunal; o trabalho voluntário; a ação política eleitoral e os novos panoramas do lazer participado.

Mais do que nunca, parece que uma renovada Gerontologia Social, lastreada por uma política e educação social, tem condições de se construir com idosos empolgados por projetos coletivos de trabalho onde se aprenda, vivencie, experimente e decida: a cidadania, a democracia, a participação, o exercício do poder, a ação descentralizada, a atenção universal, o trabalho coletivo-projetivo, a avaliação, a mudança interventiva das realidades, a produção de conhecimentos, a investigação-ação, o efeito multiplicador dos resultados, o real custo-benefício, a exiquibilidade dos projetos, a deliberação e tomada de decisões que instruem os processos democráticos, a ética com estética e a convivência solidária, que indica que um mundo mais justo e feliz é possível.

A Política Social e a Educação Social, tendo como sujeitos o idoso em seus coletivos de ação, constroem novos qualificativos interventivos-éticos na Gerontologia Social. Ao lado de outras dimensões, há na Gerontologia Social a dimensão, quem sabe complementar, lastreada por um novo conceito de público, de ajuda educativa aos grupos fragilizados da sociedade e a dimensão de empoderamento destes mesmos grupos na consecução operacional de seus direitos. Um aprendizado sócio-educativo-político com resultados em um processo democrático de ação. 


\title{
THE POLITICS, THE SOCIAL EDUCATION AND THE THIRD AGE
}

\begin{abstract}
The text favors the interdisciplinary and intervention axes that are present in Social Politics, in Social Education, and articulates them with the analogous elements contained in Gerontology. The education that is present along human life amplifies itself with the social-political elements of the participation. This participation is educative and there is some learning to those who assume it in a collective work that is present in the countless social groups of the so-called Third Age, as well as it would be necessary if it were present in the institutions said to be of social protection. However, this socialpolitical and interdisciplinary learning is immersed in a world of uncertainties that accompanies the process of getting old and old age itself. Keywords: Social Politics. Social Education. Gerontology. Third Age.
\end{abstract}

\section{REFERÊNCIAS}

CORTELETTI, Ivonne Assunta. Possibilidades e Limites de uma Educação para Idosos: metodologias e novas tecnologias. In: Encontro Ibero-Americano, 1., 2002, Caxias do Sul. Anais... Caxias do Sul: Universidade de Caxias do Sul, Universidade de Santiago de Compostela, p. 59-69, 2002.

CARIDE GÓMEZ, José Antonio. La Pedagogía social como suporte para una intervención educativa en la vejez. In: Encontro Ibero-Americano, 1., 2002, Caxias do Sul. Anais... Caxias do Sul: Universidade de Caxias do Sul; Universidade de Santiago de Compostela, p. 31-47,2002.

CARIDE GÓMEZ, José Antonio. De la identidad a los desafios de la Educación Social. In: Jornadas sobre Educación Social a les Illes Balears, 2., 1998, Palma de Mallorca. Anales... Palma de Mallorca: [s.n.], p. 1-10, 1998.

CARIDE GÓMEZ, José Antonio; MEIRA CARTEA, Pablo Ángel. La educación social en las políticas culturales: hacia una construcción pedagógica de la democracia cultural. In: Seminario Interuniversitário de Pedagogía SOCIAL, 15., 2000, Santiago de Compostela y Pontevedra. Anales... 
Santiago de Compostela y Pontevedra: Universidade de Santiago de Compostela, p. 19-42, 2000.

CARIDE GÓMEZ, José Antonio. Acción e intervención comunitárias. In: PETRUS ROTGER, Antonio Juan (Coord.). Pedagogia social. Ariel: Barcelona, p. 222-247, 1997.

DEMO, Pedro. Política Social, Educação e Cidadania. Campinas: Papirus, 1994.

GENNARI, Emílio. Senso Comum e Bom Senso: o que fazer para lidar com eles? Cadernos do CEAS. Salvador, n. 201/202, p. 27-44; p. 27-50, set/ out. e nov./dez., 2002.

GIMENO SACRISTAN, José. Educar y convivir en la cultura global: las exigencias de la ciudadania. Madrid: Morata, 2001.

NATORP, Paul. Educacion y comunidad: Pedagogia social. In: QUINTANA CABANAS, José Maria. Textos clássicos de Pedagogia social. Valência: Nau Libres, p. 7-25, 1999.

PETRUS ROTGER, Antonio. Concepto de Educación Social. Revista de Pedagogia Social. Barcelona, p. 9-39, 1997.

SÁ, Jeanete Liasch Martins de. Gerontologia e Interdisciplinaridade: fundamentos epistemológicos. In: NERI, Anita Liberalesso; DEBERT, Guita Grin. Velhice e Sociedade. Campinas: Papirus, p. 223-232,1999.

SANTOS, Boaventura de Souza. Em Defesa das Políticas Sociais. Cadernos IdeaAção: II FÓRUM SOCIAL MUNDIAL. Porto Alegre, v. 1, p. 21-32, 2002.

SCHIRRMACHER, Frank. A Revolução dos Idosos: como será o novo choque de gerações, o que muda no mundo com o aumento da população mais velha. Rio de Janeiro: Campus, 2005.

VILLAR, María B. Caballo. A Cidade Educadora: nova perspectiva de organização e Intervenção Municipal. Lisboa: Instituto Piaget, 2001. 